\title{
Functional grading of viscoelastic defined hot mix asphalt layers
}

\author{
Murat Bostancioğlu \\ Department of Civil Engineering, Sivas Cumhuriyet University \\ 58140, Sivas (Turkey) \\ bostancioglu@cumhuriyet.edu.tr \\ https://orcid.org/0000-0001-6820-2213
}

Manuscript Code: 13750

Date of Acceptance/Reception: 23.10.2020/10.03.2020

DOI: 10.7764/RDLC.19.3.258

\begin{abstract}
In the design of layered flexible pavements with the mechanistic-empirical (M-E) method, the material characterization of layers is critical for the correct calculation of mechanical responses. The surface layers of flexible pavements produced as hot mix asphalt (HMA) behave as a viscoelastic material under real field conditions. In this study, in which the HMA surface layer was defined viscoelastic by creep-compliance method, functional grading was applied to the surface layer at the same time to increase the fatigue strength of the pavement. Functional grading application was performed in the form of 3,5, 7, and 9 sub-layers with linear and exponential functions. The pavement life values due to the mechanical responses that occurred in the pavement were determined by the Asphalt Institute and Shell methods. The study results show that the fatigue strength of the viscoelastic surface layer increases significantly as a result of functional grading. Especially in sections with exponential grading, an improvement of more than $10 \%$ was achieved even when a small number of sub-layers used. These results show that functional grading can also be successfully applied in field studies, and even with three sub-layers, significant improvements can be provided.
\end{abstract}

Key words: Hot mix asphalt, mechanistic-empirical pavement design, creep-compliance, viscoelastic material, functional grading, fatigue.

Introduction

When flexible pavement layers are subjected to wheel load and environmental influences, critical stress and strains occur at various locations through the depth of the pavement. In the mechanistic-empirical (M-E) design method (Huang, 2004), which is one of the methods used in the design of flexible pavements, these stresses and strains occurring in the pavement are calculated mechanically, and the values obtained are used for the pavement life estimation with the help of empirical transfer functions (Ali, H. A. Tayabji, 1998; Behiry, 2012; Gedafa, 2006; Jeong, 2005; Mousa, AboHashema, Gadallah, \& Mousa, 2015).

The two critical distress types used in pavement life estimation are fatigue and rutting. While the maximum compressive strain values occurring on the top of the subgrade are used in the rutting lifetime estimation of the pavement, the tensile strain values occurring under the hot mix asphalt (HMA) surface layer are also used in the fatigue-based pavement life estimate (Aktaş, Aytekin, \& Aslan, 2019; Behiry, 2012; Mousa et al., 2015).

In the M-E design method, material identification data are needed to model the pavement layers and to calculate critical stress and strain.Flexible pavements are often modeled as multilayered linear elastic systems. Burmister's elastic layer theory is one of the most practical and common mechanical models used for this purpose. The mechanical parameters needed in this model, in which all layers in the system are considered homogeneous and isotropic, are the elasticity modulus (E) and Poisson's ratio (U) of the layers (Huang, 2004; Jeong, 2005; Singh \& Sahoo, 2020). However, under real field conditions, HMA layers act as a viscoelastic material, and their mechanical responses depend on temperature and loading time (Ahmed \& Erlingsson, 2016; Chen, Pan, \& Green, 2009; Jeong, 2005; Koohmishi, 2013).

The first of the two basic methods used in the definition of viscoelastic materials are mechanical models in which the elastic behavior of viscoelastic materials is characterized by the spring and the viscous by the dash-pot.

The Maxwell model, in which the spring and dash-pot is connected in series, the Kelvin model in which it is connected in parallel, the Burgers model, is the combination of Maxwell and Kelvin models, and Kelvin-Voigt model are frequently used in the viscoelastic definition of asphalt paving layers (Ambassa, Allou, Petit, \& Eko, 2013; Huang, 2004; Mejłun, Judycki, \& Dołzycki, 2017).

Another common method used to characterize the responses of viscoelastic materials under load is to measure the creep behavior of the material at different temperatures and different loading times (Jeong, 2005). In the creep compliance method preferred because it is simpler than mechanical models, the Poisson's ratio, which has little effect on pavement behavior, is considered elastic and time-independent. 
Therefore, only $E$ is considered viscoelastic and time-dependent. Creep compliance $(D(t))$ value is defined by Equation 1(Huang, 2004; Safi, Hossain, Wu, Al-Qadi, \& Ozer, 2018).

$D(t)=\frac{\varepsilon(t)}{\sigma}$

In the equation, $\varepsilon(t)$ refers to the time-dependent strain under constant stress $(\sigma)$. Accordingly, $D(t)$ is the reciprocal of E under constant stress.

The creep test applied to HMA is an important experiment carried out to determine the strain of the material, both independent of time (elastic) and time-dependent (viscoelastic and plastic). The results obtained from this experiment at low temperatures are used for the prediction of thermal cracking development, and the values obtained at high temperatures are used for the prediction of rutting.

Test methods used to measure the creep behavior of HMA can be listed as, uniaxial, triaxial, and indirect tensile tests. Uniaxial testing is more preferred because it is simple and reflects the in-situ behavior of flexible pavements. The triaxial test also reflects the in-situ conditions well due to the horizontal confinement, but this method cannot be widely used because of the complexity of equipment setting up (Safi et al., 2018).

Indirect tensile test (IDT) that is preferred by the Strategic Highway Research Program (SHRP) characterizes the thermal cracking performance of HMA at low temperatures (Marasteanu et al., 2012; Richardson \& Lusher, 2008; Safi et al., 2018). In this experiment, creep compliances of different asphalt concrete mixtures are obtained according to the standard AASHTO T 322-07 method (Christensen \& Bonaquist, 2004; Jeong, 2005; Richardson \& Lusher, 2008; Safi et al., 2018).

Functionally graded materials (FGMs) are widely used in many different engineering applications, such as shipbuilding, automotive and aerospace industry, civil, nuclear power plants, and medical devices, thanks to their attractive mechanical properties (Miteva, 2014; Xu \& Meng, 2018; Zhang \& Yang, 2020).The mechanical properties of these materials such as $E, U$, shear modulus, and conductivity, show a continuous and gradual change along with one or both directions of the material. This situation increases the mechanical capacity of the material desirably. Combining specific ceramic properties such as high temperature and corrosion resistance and specific metal properties such as high mechanical strength and toughness in a single material are typical examples of functional grading (Ghayesh, 2018; Jin \& Paulino, 2002). Smaller stress concentrations, increased thermal properties, high fracture toughness, and reduction of thermal stresses are examples of the benefits of FGMs (Hilton \& Lee, 2012).

Functional grading provides a gradual transition from one layer to another, which eliminates the sharp interfaces that the failure begins, and is considered as an alternative to layered composites as well as to homogeneous materials (Ashwinkumar A kokanee, 2017; Mahamood, Akinlabi, Shukla, \& Pityana, 2012; Miteva, 2014).

In the functional grading of layered structures, the layers are divided into sub-layers, and their mechanical properties are changed throughout the depth by a certain function or the power-law (Çömez, 2015; Guler \& Erdogan, 2004; Liu \& Wang, 2008; Liu, Wang, \& Zhang, 2008). The usual power law is widely used in the analysis of civil engineering structures such as rods, beams, plates, and shells (Chakraborty, Gopalakrishnan, \& Reddy, 2003; Demirbas, 2017; Kahya \& Turan, 2017; Xu \& Meng, 2018).

Viscoelastic functional graded materials can also be considered as a member of the FGMs family. In viscoelastic functional graded materials, the material properties change not only in a certain direction but also depending on the time (Zhang \& Yang, 2020). HMA layers are a good example of materials best suited for viscoelastic grading. The material properties of asphalt pavements vary significantly depending on aging and temperature (Dave, Paulino, \& Buttlar, 2011).

Flexible pavements consist of surface, base and, sub-base layers whose mechanical properties are quite different from each other. In this layered structure, the bituminous surface layer exhibits a viscoelastic behavior (Ahmed \& Erlingsson, 2016; Mistry \& Roy, 2020; Safi et al., 2018), while the granular base and sub-base layers can be characterized as linear elastic or non-linear elastic.

While linear elasticity is accepted as a valid method in relatively thick pavement layers, non-linear characteristics of materials should be considered in thin layers. The most important parameter used in non-linear identification of 
granular layers is the resilient modulus (Mr) (Abd Alla, 2006; Ghadimi \& Nikraz, 2017; Ng, Henrichs, Ksaibati, \& Wulff, 2018; Titi \& Matar, 2018).

In this study, which aims to analyze the pavement life change with the M-E design method as a result of the functional grading of the bituminous surface layer showing viscoelastic behavior, the surface layer divided into 3,5,7 and 9 sublayers and was graded with linear and exponential functions. Since the main purpose of the study is to examine the effects of viscoelastic functional grading, the granular base and sub-base layers are defined as linear elastic.

It is thought that the study will provide a unique contribution to the studies in the field of pavement engineering in terms of creating an example that is not included in the literature on the functional grading of the viscoelastic layers defined with the creep compliance method and discussing the benefits of this method on pavement

Materials and Methods

Layer thicknesses were defined on the z-axis by selecting a conventional flexible pavement section (Figure 3 ). The creep compliance method (Huang, 2004) was used for the viscoelastic definition of the surface layer and the time-dependent $D(t)$ values of the HMA layer and the modulus of elasticity at the relevant time $(E(t))$ are given in Table 1. Linear elastic layer parameters ( $E$ and $U$ ) of the base, sub-base, and subgrade are shown in Figure 1.

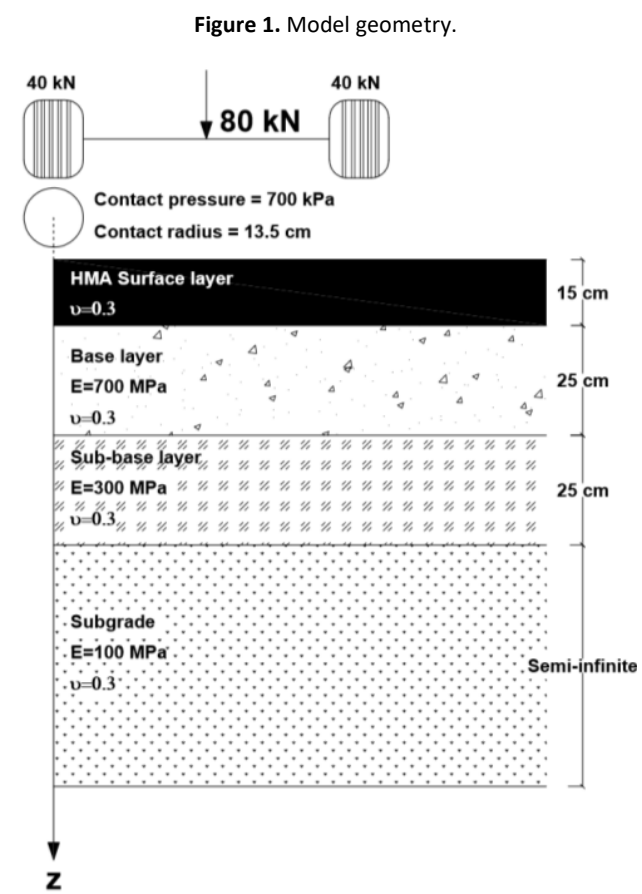

In the mechanical analysis, the axle load on the single axle is determined as $80 \mathrm{kN}$ ( 8.2 tons), and this load is distributed equally on the wheels (Moreno, Navarro, \& Zeballos, 2017). Wheel internal pressure (contact pressure) (CP) was chosen as $700 \mathrm{kPa}$ (Hadi \& Bodhinayake, 2003). The contact radius (CR) for the circular wheel contact area providing this internal pressure was calculated as $13.5 \mathrm{~cm}$.

In the analysis, the contact surfaces between the layers are defined as bonded. KENLAYER program was used to determine the stress and strain values. The program has been successfully used to calculate the mechanical responses of linear elastic, non-linear elastic, and viscoelastic defined multilayered flexible pavements under different loading conditions for any chosen depth and lateral distance (Chegenizadeh, Keramatikerman, \& Nikraz, 2016; Huang, 2004; Muniandy, Aburkaba, \& Thamer, 2013).

For the functional grading process, the viscoelastic HMA layer is divided into sub-layers (3, 5, 7 and 9 sub-layers). Grading was applied according to a certain function, and linear and exponential grading functions were used for this purpose. It is assumed that the $\mathrm{D}(\mathrm{t})$ value calculated for the mid-depth of each sub-layer with the related functions represents the entire sub-layer.

In the use of grading functions, $1 / D(t)$ values were used instead of $D(t)$ values to reduce complexity and change the modulus of elasticity $(1 / D(t))$ in compliance with a certain rule. Accordingly, calculated $E(t)$ values are converted back to $D(t)$ and entered as viscoelastic material identification data to KENLAYER. 
In the linear grading process, the $E(t)$ value at any moment of the middle sub-layer is kept equal to the non-graded $E(t)$ value, and the $E(t)$ values of the other sub-layers have been changed with a certain linear increase or decrease value in the $\mathrm{z}$-axis direction. Increase or decrease values are determined as 100, 250, and $500 \mathrm{MPa}$. An illustration of this application is given in Figure 2.

Table 1.Time-dependent $\mathrm{D}(\mathrm{t})$ and $\mathrm{E}(\mathrm{t})$ values (Richardson \& Lusher, 2008)

\begin{tabular}{cccc}
\multicolumn{4}{c}{ Table 1.Time-dependent $\mathrm{D}(\mathrm{t})$ and $\mathrm{E}(\mathrm{t})$ values (Richardson \& Lusher, 2008) } \\
\hline Temperature $\left({ }^{\circ} \mathrm{C}\right)$ & Time $(\mathrm{sec})$ & $\mathrm{D}(\mathrm{t})(1 / \mathrm{GPa})$ & $\mathrm{E}(\mathrm{t})(\mathrm{MPa})$ \\
\hline 1 & 0.03631 & 27540,62 \\
2 & 0.03720 & 26881,72 \\
-20 & 5 & 0.03906 & 25601,64 \\
& 10 & 0.04095 & 24420,02 \\
& 20 & 0.04225 & 23668,64 \\
50 & 0.04574 & 21862,7 \\
& 100 & 0.04750 & 21052,63 \\
\hline
\end{tabular}

Figure 2. Linear grading application with 3 sub-layers and $500 \mathrm{MPa}$ increasing for $\mathrm{t}=1 \mathrm{sec}$.

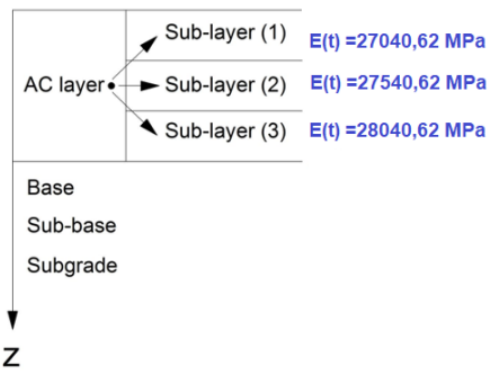

In the exponential grading process, the modulus of elasticity $(E(i, t))$ of any sub-layer $(i)$ at the moment $(t)$ is calculated by Equation 2 (Çömez, 2015; Giannakopoulos \& Pallot, 2000; Ramirez, Heyliger, \& Pan, 2006). In the equation, Etop is the modulus of elasticity at the top of the HMA layer, $z$ is mid-depth $(\mathrm{m})$ of the sub-layer from top of the related layer, and $\mu$ inhomogeneity coefficient. In this study, this coefficient was taken as $1,-1,0.5$ and -0.5 for different variations.

$E(i, t)=E_{\text {top }} e^{\eta z}$

In the functional grading process, the average elasticity modulus value $\left(E_{\text {avg }}\right)$ of the sub-layers was calculated with Equation 3, and this value was provided to be equal to the non-graded layer's elasticity module (Bostancioğlu, 2019). Thus, the viscoelastic surface layer is neither reinforced nor weakened according to the non-graded situation. Changes in pavement life are associated only with functional grading.

$E_{\text {avg }}=\sum\left(E_{i} d_{i}\right) / \sum d_{i}$

In the equation, $E_{i}$ denotes the modulus of elasticity and di denotes the thickness of any sub-layer (i).

In the M-E design method, mechanical responses (displacement, stress, and strain) must be converted into a parameter that reflects the pavement performance. The most commonly used parameters for this purpose are pavement life values based on the fatigue and rutting failure.

Different models have been proposed by different agencies in the transfer of mechanical responses to pavement life values (Behiry, 2012). The general form of these models is given in Equation 4 and 5 , and the coefficients (f1- $f 5$ ) used in the equations are given in Table 2. In the current study, transfer models of Asphalt Institute (AI) and Shell Research (SR) were taken into consideration.

$N_{f}=f 1 \varepsilon_{r}^{-f 2} E 1^{-f 3}$ 
In the equations, the $N_{f}$ and $N_{r}$ indicate the number of load applications to fatigue and rutting failure respectively, $\varepsilon_{r}$ is the horizontal tensile strain at the bottom of the HMA layer, $\varepsilon_{v}$ is the compressive strain on the subgrade and the E1 is the elasticity modulus (psi) of the HMA layer. E1 value is used as $E_{\text {avg }}$ in sections with functional grading.

\begin{tabular}{|c|c|c|c|c|c|c|c|c|}
\hline & 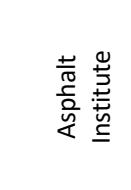 & 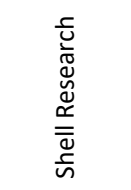 & 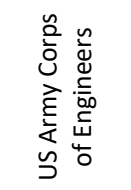 & 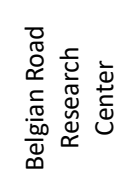 & 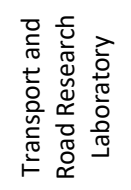 & 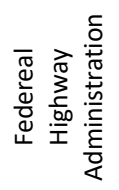 & 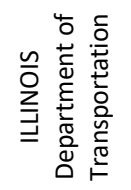 & 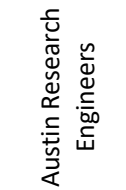 \\
\hline f1 & 0.0795 & 0.0685 & 497.156 & $4.92 \mathrm{E}-14$ & $1.66 \mathrm{E}-10$ & 0.1001 & $5.00 \mathrm{E}-06$ & $4.88 \mathrm{E}-01$ \\
\hline f2 & 3.291 & 5.671 & 5 & 4.76 & 4.32 & 3.565 & 3 & 3.0312 \\
\hline f3 & 0.854 & 2.363 & 2.66 & 0 & 0 & 1.474 & 0 & 0.6529 \\
\hline $\mathrm{f} 4$ & 1.37E-09 & $6.15 E-07$ & $1.81 \mathrm{E}-15$ & $3.05 \mathrm{E}-09$ & $1.13 \mathrm{E}-06$ & --- & --- & --- \\
\hline f5 & 4.477 & 4 & 6.527 & 4.35 & 3.75 & --- & --- & --- \\
\hline
\end{tabular}

In the study, the non-graded section was defined as the "control section". The coding system used for sections with functional grading is briefly described in Table 3.

\begin{tabular}{ll}
\hline Coding & Description \\
\hline LG3_100i & $\begin{array}{l}\text { Linear Grading, 3 sub-layers, elasticity modulus increases } 100 \mathrm{MPa} \text { from top to } \\
\text { bottom for each sub-layer }\end{array}$ \\
& $\begin{array}{l}\text { Linear Grading, 3 sub-layers, elasticity modulus decreases } 100 \mathrm{MPa} \text { from top to } \\
\text { bottom for each sub-layer }\end{array}$ \\
EG_3_05 & $\begin{array}{l}\text { Exponential Grading, 3 sub-layers, inhomogeneity coefficient is 0.5 } \\
\text { EG_3_M05 }\end{array}$ \\
\hline
\end{tabular}

Equation 6 was used to determine the change $(C(\%))$ provided by the functional grading process compared to the control section.

$C(\%)=\frac{N_{i}-N_{\text {contol }}}{N_{\text {control }}} x 100$

In the equation, $N_{i}$ represents the calculated $N_{f}$ or $N_{r}$ value for any section, $N_{\text {control }}$ shows the calculated $N_{f}$ or $N_{r}$ value for the control section.

\section{Results and Discussion}

As a result of the mechanical analysis for the control section, the strain values occurring under the HMA layer and on the subgrade and the pavement life values calculated based on these values are given in Table 4.

In addition to the control section, 48 functionally graded sections were divided into two groups as sections where $\mathrm{E}$ was increased from top to bottom (Group 1) and sections that were decreased (Group 2). The road life and C(\%) values calculated according to $\mathrm{Al}$ and Shell methods for both groups are given in Tables 5 and 6 for $\mathrm{t}=1 \mathrm{sec}$ loading time.

When Tables 5 and 6 are analyzed, it is determined that $\mathrm{N}_{\mathrm{f}}$ values increase by $7.08 \%$ for the Al method and $12.51 \%$ for the Shell method in group 1. In this case, although the $\mathrm{N}_{\mathrm{r}}$ values have decreased, it is seen that the reduction rates are not excessive. In Group 2 sections, it has been determined that the pavement life due to rutting has increased slightly, but the pavement life values due to fatigue have decreased significantly. According to these values, it is clearly seen that the functions and parameters used in the functional grading contribute more positively to the fatigue life of the road than rutting life. 
Table 4. Mechanical analysis results and $\mathrm{N}_{\mathrm{r}}$ and $\mathrm{N}_{\mathrm{f}}$ values for the control section.

\begin{tabular}{ccccccc}
\hline & Fatigue parameter & Rutting parameter & \multicolumn{2}{c}{ Fatigue Life $\left(\mathrm{N}_{\mathrm{f}}\right)$} & \multicolumn{2}{c}{ Rutting Life $\left(\mathrm{N}_{\mathrm{r}}\right)$} \\
$\mathrm{t}(\mathrm{sec})$ & $\varepsilon r(\mathrm{E}-05)$ & $\varepsilon^{2}(\mathrm{E}-04)$ & Al & Shell & Al & Shell \\
\hline 1 & $-4,034$ & 1,118 & 52996590,41 & 143325907,3 & 672739011,4 & 3936478661 \\
2 & $-4,100$ & 1,127 & 51290193,57 & 138422485,5 & 649018677,3 & 3812233133 \\
5 & $-4,233$ & 1,144 & 48139571,52 & 129613989,3 & 606942089,8 & 3590633000 \\
10 & $-4,365$ & 1,16 & 45304257,32 & 121763251,6 & 570350923,9 & 3396590252 \\
20 & $-4,454$ & 1,171 & 43539296,05 & 116916820,1 & 546753218,1 & 3270751396 \\
50 & $-4,685$ & 1,199 & 39450270,27 & 105875784,1 & 491866318,5 & 2975763300 \\
100 & $-4,799$ & 1,212 & 37643635,93 & 101002476,9 & 468683147,9 & 2850129783 \\
\hline
\end{tabular}

This increase in fatigue strength of the pavement can be explained by 2 phenomena.

i) Strengthening the HMA-base interface through the increase of E from top to bottom,

ii) The basic parameter used in $\mathrm{N}_{f}$ calculation (Equation 4 ) is the tensile strain at the HMA-base interface.

Table 5. $\mathrm{N}_{\mathrm{f}}, \mathrm{N}_{\mathrm{r}}$ and $\mathrm{C}(\%)$ values for group 1 .

\begin{tabular}{|c|c|c|c|c|c|c|c|c|c|}
\hline \multirow[b]{2}{*}{ Coding } & \multirow[b]{2}{*}{$t(\sec )$} & \multicolumn{2}{|c|}{ Fatigue Life $\left(\mathrm{N}_{\mathrm{f}}\right)$} & \multicolumn{2}{|c|}{ Rutting Life $\left(\mathrm{N}_{\mathrm{r}}\right)$} & \multicolumn{2}{|c|}{ Fatigue Life (C\%) } & \multicolumn{2}{|c|}{ Rutting Life (C\%) } \\
\hline & & $\mathrm{Al}$ & Shell & $\mathrm{Al}$ & Shell & $\mathrm{Al}$ & Shell & $\mathrm{Al}$ & Shell \\
\hline LG3_100i & 1 & $5.317 \mathrm{E}+07$ & $1.441 \mathrm{E}+08$ & $6.727 \mathrm{E}+08$ & $3.936 \mathrm{E}+09$ & 0.33 & 0.56 & 0.00 & 0.00 \\
\hline LG3_200i & 1 & $5.339 E+07$ & $1.452 \mathrm{E}+08$ & $6.701 \mathrm{E}+08$ & $3.922 \mathrm{E}+09$ & 0.74 & 1.27 & -0.40 & -0.36 \\
\hline LG3_300i & 1 & $5.361 \mathrm{E}+07$ & $1.462 \mathrm{E}+08$ & $6.701 \mathrm{E}+08$ & $3.922 E+09$ & 1.15 & 1.99 & -0.40 & -0.36 \\
\hline LG3_500i & 1 & $5.405 E+07$ & $1.483 E+08$ & $6.674 \mathrm{E}+08$ & $3.908 \mathrm{E}+09$ & 1.98 & 3.44 & -0.80 & -0.71 \\
\hline LG5_100i & 1 & $5.334 \mathrm{E}+07$ & $1.449 \mathrm{E}+08$ & $6.701 E+08$ & $3.922 \mathrm{E}+09$ & 0.66 & 1.13 & -0.40 & -0.36 \\
\hline LG5_200i & 1 & $5.374 \mathrm{E}+07$ & $1.468 \mathrm{E}+08$ & $6.701 \mathrm{E}+08$ & $3.922 E+09$ & 1.40 & 2.42 & -0.40 & -0.36 \\
\hline LG5_300i & 1 & $5.418 \mathrm{E}+07$ & $1.489 \mathrm{E}+08$ & $6.674 \mathrm{E}+08$ & $3.908 \mathrm{E}+09$ & 2.23 & 3.88 & -0.80 & -0.71 \\
\hline LG5_500i & 1 & $5.494 \mathrm{E}+07$ & $1.525 \mathrm{E}+08$ & $6.647 E+08$ & $3.895 E+09$ & 3.68 & 6.42 & -1.19 & -1.07 \\
\hline LG7_100i & 1 & $5.356 \mathrm{E}+07$ & $1.460 \mathrm{E}+08$ & $6.701 E+08$ & $3.922 E+09$ & 1.07 & 1.85 & -0.40 & -0.36 \\
\hline LG7_200i & 1 & $5.414 E+07$ & $1.487 E+08$ & $6.701 \mathrm{E}+08$ & $3.922 \mathrm{E}+09$ & 2.15 & 3.73 & -0.40 & -0.36 \\
\hline LG7_300i & 1 & $5.472 \mathrm{E}+07$ & $1.514 \mathrm{E}+08$ & $6.674 \mathrm{E}+08$ & $3.908 \mathrm{E}+09$ & 3.25 & 5.66 & -0.80 & -0.71 \\
\hline LG7_500i & 1 & $5.586 \mathrm{E}+07$ & $1.569 \mathrm{E}+08$ & $6.621 \mathrm{E}+08$ & $3.881 E+09$ & 5.40 & 9.49 & -1.59 & -1.42 \\
\hline LG9_100i & 1 & $5.374 \mathrm{E}+07$ & $1.468 \mathrm{E}+08$ & $6.701 \mathrm{E}+08$ & $3.922 \mathrm{E}+09$ & 1.40 & 2.42 & -0.40 & -0.36 \\
\hline LG9_200i & 1 & $5.449 E+07$ & $1.504 \mathrm{E}+08$ & $6.674 \mathrm{E}+08$ & $3.908 \mathrm{E}+09$ & 2.82 & 4.92 & -0.80 & -0.71 \\
\hline LG9_300i & 1 & $5.526 \mathrm{E}+07$ & $1.540 \mathrm{E}+08$ & $6.647 \mathrm{E}+08$ & $3.895 E+09$ & 4.28 & 7.48 & -1.19 & -1.07 \\
\hline LG9_500i & 1 & $5.675 \mathrm{E}+07$ & $1.613 \mathrm{E}+08$ & $6.594 \mathrm{E}+08$ & $3.867 E+09$ & 7.08 & 12.51 & -1.98 & -1.77 \\
\hline EG_3_05 & 1 & $5.449 \mathrm{E}+07$ & $1.504 \mathrm{E}+08$ & $6.674 \mathrm{E}+08$ & $3.908 \mathrm{E}+09$ & 2.82 & 4.92 & -0.80 & -0.71 \\
\hline EG_3_1 & 1 & $5.605 \mathrm{E}+07$ & $1.578 \mathrm{E}+08$ & $6.621 \mathrm{E}+08$ & $3.881 E+09$ & 5.75 & 10.12 & -1.59 & -1.42 \\
\hline EG_5_05 & 1 & $5.467 \mathrm{E}+07$ & $1.512 \mathrm{E}+08$ & $6.674 \mathrm{E}+08$ & $3.908 \mathrm{E}+09$ & 3.16 & 5.51 & -0.80 & -0.71 \\
\hline EG_5_1 & 1 & $5.642 E+07$ & $1.596 \mathrm{E}+08$ & $6.621 E+08$ & $3.881 E+09$ & 6.46 & 11.39 & -1.59 & -1.42 \\
\hline E_G_7_05 & 1 & $5.472 \mathrm{E}+07$ & $1.514 \mathrm{E}+08$ & $6.674 \mathrm{E}+08$ & $3.908 \mathrm{E}+09$ & 3.25 & 5.66 & -0.80 & -0.71 \\
\hline EG_7_1 & 1 & $5.656 \mathrm{E}+07$ & $1.603 E+08$ & $6.621 \mathrm{E}+08$ & $3.881 E+09$ & 6.73 & 11.87 & -1.59 & -1.42 \\
\hline E_G_9_05 & 1 & $5.476 \mathrm{E}+07$ & $1.517 \mathrm{E}+08$ & $6.674 \mathrm{E}+08$ & $3.908 \mathrm{E}+09$ & 3.33 & 5.81 & -0.80 & -0.71 \\
\hline EG_9_1 & 1 & $5.666 \mathrm{E}+07$ & $1.608 \mathrm{E}+08$ & $6.621 \mathrm{E}+08$ & $3.881 E+09$ & 6.90 & 12.19 & -1.59 & -1.42 \\
\hline
\end{tabular}

When the graphs (Figures 3 and 4) drawn for $t=1 \mathrm{sec}$ are examined to determine the effect of the functions and the parameters used in the process of functional grading on the $C(\%)$ values; It is observed that the $C(\%)$ values increase as the number of sub-layers increases between the sections graded with the linear grading function. According to the Shell method, the highest $C(\%)$ value calculated with 3 sub-layers was 3.44 , while the $C(\%)$ values for 5,7 , and 9 sub-layers were $6.42,9.49$ and 12.51 , respectively.

In the examination made between the sections with the same sub-layer number, the $\mathrm{C}(\%)$ values increased as the stiffness increase value in the z-direction increased. The increase in the stiffness between the sub-layers from $100 \mathrm{MPa}$ to $500 \mathrm{MPa}$, increased the $\mathrm{C}(\%)$ values calculated according to the Shell method by $6.14,5.68,5.13$, and 5.17 times for 
the 3,5,7, and 9 sub-layers, respectively, compared to the control section.According to these results, it can be said that the stiffness increase amount is a more effective parameter for the sections with less sub-layer.

Table 6. $\mathrm{N}_{\mathrm{f}}, \mathrm{N}_{\mathrm{r}}$ and $\mathrm{C}(\%)$ values for group 2.

\begin{tabular}{|c|c|c|c|c|c|c|c|c|c|}
\hline \multirow[b]{2}{*}{ Coding } & \multirow[b]{2}{*}{$\mathrm{t}(\mathrm{sec})$} & \multicolumn{2}{|c|}{ Fatigue Life $\left(\mathrm{N}_{\mathrm{f}}\right)$} & \multicolumn{2}{|c|}{ Rutting Life $\left(\mathrm{N}_{\mathrm{r}}\right)$} & \multicolumn{2}{|c|}{ Fatigue Life (C\%) } & \multicolumn{2}{|c|}{ Rutting Life (C\%) } \\
\hline & & $\mathrm{Al}$ & Shell & Al & Shell & $\mathrm{Al}$ & Shell & Al & Shell \\
\hline LG3_100D & 1 & $5.274 E+07$ & $1.421 \mathrm{E}+08$ & $6.727 E+08$ & $3.936 \mathrm{E}+09$ & -0.49 & -0.84 & 0.00 & 0.00 \\
\hline LG3_200D & 1 & $5.252 E+07$ & $1.411 \mathrm{E}+08$ & $6.727 E+08$ & $3.936 E+09$ & -0.89 & -1.53 & 0.00 & 0.00 \\
\hline LG3_300D & 1 & $5.231 E+07$ & $1.401 \mathrm{E}+08$ & $6.754 E+08$ & $3.951 E+09$ & -1.29 & -2.22 & 0.40 & 0.36 \\
\hline LG3_500D & 1 & $5.185 E+07$ & $1.380 E+08$ & $6.754 E+08$ & $3.951 E+09$ & -2.17 & -3.71 & 0.40 & 0.36 \\
\hline LG5_100D & 1 & $5.252 E+07$ & $1.411 \mathrm{E}+08$ & $6.727 E+08$ & $3.936 \mathrm{E}+09$ & -0.89 & -1.53 & 0.00 & 0.00 \\
\hline LG5_200D & 1 & $5.214 \mathrm{E}+07$ & $1.394 E+08$ & $6.754 \mathrm{E}+08$ & $3.951 E+09$ & -1.61 & -2.77 & 0.40 & 0.36 \\
\hline LG5_300D & 1 & $5.172 E+07$ & $1.374 \mathrm{E}+08$ & $6.754 E+08$ & $3.951 \mathrm{E}+09$ & -2.41 & -4.11 & 0.40 & 0.36 \\
\hline LG5_500D & 1 & $5.093 E+07$ & $1.338 \mathrm{E}+08$ & $6.782 E+08$ & $3.965 E+09$ & -3.90 & -6.62 & 0.80 & 0.72 \\
\hline LG7_100D & 1 & $5.240 E+07$ & $1.405 E+08$ & $6.754 E+08$ & $3.951 \mathrm{E}+09$ & -1.13 & -1.95 & 0.40 & 0.36 \\
\hline LG7_200D & 1 & $5.180 E+07$ & $1.378 \mathrm{E}+08$ & $6.754 E+08$ & $3.951 E+09$ & -2.25 & -3.85 & 0.40 & 0.36 \\
\hline LG7_300D & 1 & $5.122 E+07$ & $1.351 \mathrm{E}+08$ & $6.782 E+08$ & $3.965 E+09$ & -3.35 & -5.70 & 0.80 & 0.72 \\
\hline LG7_500D & 1 & $5.004 E+07$ & $1.298 \mathrm{E}+08$ & $6.809 E+08$ & $3.979 E+09$ & -5.58 & -9.42 & 1.21 & 1.08 \\
\hline LG9_100D & 1 & $5.223 E+07$ & $1.398 \mathrm{E}+08$ & $6.754 E+08$ & $3.951 E+09$ & -1.45 & -2.49 & 0.40 & 0.36 \\
\hline LG9_200D & 1 & $5.147 \mathrm{E}+07$ & $1.363 E+08$ & $6.782 E+08$ & $3.965 E+09$ & -2.88 & -4.91 & 0.80 & 0.72 \\
\hline LG9_300D & 1 & $5.069 E+07$ & $1.327 \mathrm{E}+08$ & $6.809 E+08$ & $3.979 E+09$ & -4.36 & -7.39 & 1.21 & 1.08 \\
\hline LG9_500D & 1 & $4.917 \mathrm{E}+07$ & $1.259 \mathrm{E}+08$ & $6.836 E+08$ & $3.993 \mathrm{E}+09$ & -7.23 & -12.13 & 1.62 & 1.44 \\
\hline EG_3_M05 & 1 & $5.147 E+07$ & $1.363 E+08$ & $6.782 E+08$ & $3.965 E+09$ & -2.88 & -4.91 & 0.80 & 0.72 \\
\hline EG_3_M1 & 1 & $5.004 \mathrm{E}+07$ & $1.298 \mathrm{E}+08$ & $6.836 \mathrm{E}+08$ & $3.993 E+09$ & -5.58 & -9.42 & 1.62 & 1.44 \\
\hline EG_5_M05 & 1 & $5.130 E+07$ & $1.355 E+08$ & $6.782 E+08$ & $3.965 E+09$ & -3.20 & -5.44 & 0.80 & 0.72 \\
\hline EG_5_M1 & 1 & $4.976 E+07$ & $1.286 \mathrm{E}+08$ & $6.836 E+08$ & $3.993 E+09$ & -6.11 & -10.29 & 1.62 & 1.44 \\
\hline E_G_7_M05 & 1 & $5.126 E+07$ & $1.353 E+08$ & $6.782 E+08$ & $3.965 E+09$ & -3.27 & -5.57 & 0.80 & 0.72 \\
\hline EG_7_M1 & 1 & $4.968 \mathrm{E}+07$ & $1.282 \mathrm{E}+08$ & $6.836 E+08$ & $3.993 \mathrm{E}+09$ & -6.26 & -10.54 & 1.62 & 1.44 \\
\hline E_G_9_M05 & 1 & $5.130 E+07$ & $1.355 \mathrm{E}+08$ & $6.782 E+08$ & $3.965 E+09$ & -3.20 & -5.44 & 0.80 & 0.72 \\
\hline EG_9_M1 & 1 & $4.964 E+07$ & $1.280 \mathrm{E}+08$ & $6.836 \mathrm{E}+08$ & $3.993 E+09$ & -6.33 & -10.66 & 1.62 & 1.44 \\
\hline
\end{tabular}

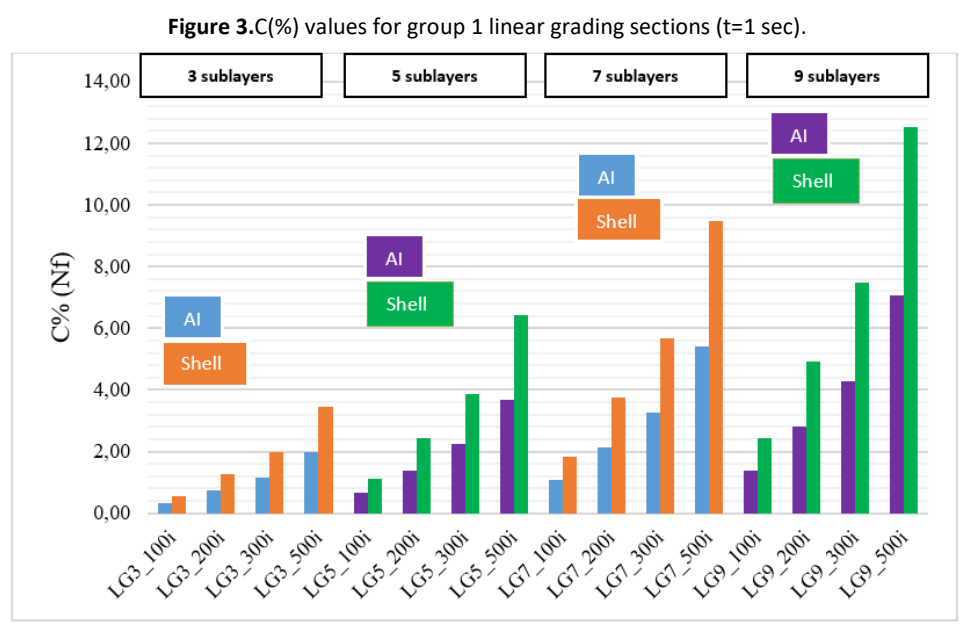

When the Figure 4 showing the $C(\%)$ values at the time of $t=1 \mathrm{sec}$ for the exponential grading sections, it is seen that the $\mathrm{C}(\%)$ values increase due to the increase in the number of sub-layers. However, this increasing rate is much lower compared to linear grading sections. It is observed that the increase of the inhomogeneity coefficient from 0.5 to 1 for exponential grading sections with the same sub-layer number increases fatigue strength. 
Figure 4. $C(\%)$ values for group 1 exponential grading sections ( $t=1 \mathrm{sec}$ ).

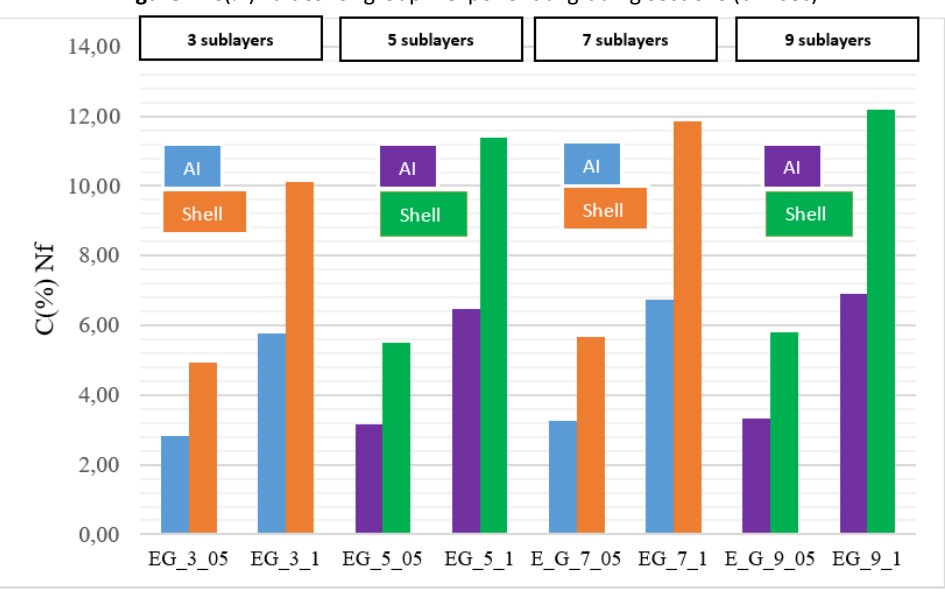

When Figures 5 and 6 , in which $C(\%)$ values are evaluated together depending on the number of sub-layer, stiffness, and loading time, the positive effect of the increase in all these parameters is seen for linear grading sections. However, no explicit change was observed in the exponential grading sections due to the increase in loading time. $\mathrm{C}(\%)$ values increased due to the increase in loading time for all sections with the same sub-layer number in sections with linear grading (Figure 5; Row 1 and 2 for 5 sub-layers; Row 3 and 4 for 7 sub-layers). $C(\%)$ values increased due to the increase in loading time for all sections with the same sub-layer number in sections with linear grading. No significant $\mathrm{C}(\%)$ increase was observed in exponential grading sections due to increasing time. However, the $C(\%)$ values obtained for all loading time values in these sections are already close to the levels of $t=50 \mathrm{sec}$ and $t=100 \mathrm{sec}$ in the linear grading sections. For example, for $t=50 \mathrm{sec}$ and $t=100 \mathrm{sec}$ loading times in LG7_500i section, $C(\%)$ values are 11.90 and 12.41 respectively, for $t=1,2,5,10,20,50$ and 100 sec in EG_7_1 section with the same sub-layer number, the values were obtained as $11.87,12.14,12.04,11.95,11.98,11.77$ and 11.87 , respectively.In other words, while linear grading sections are more effective at long loading times, the exponential grading shows similar efficiency at all loading times.

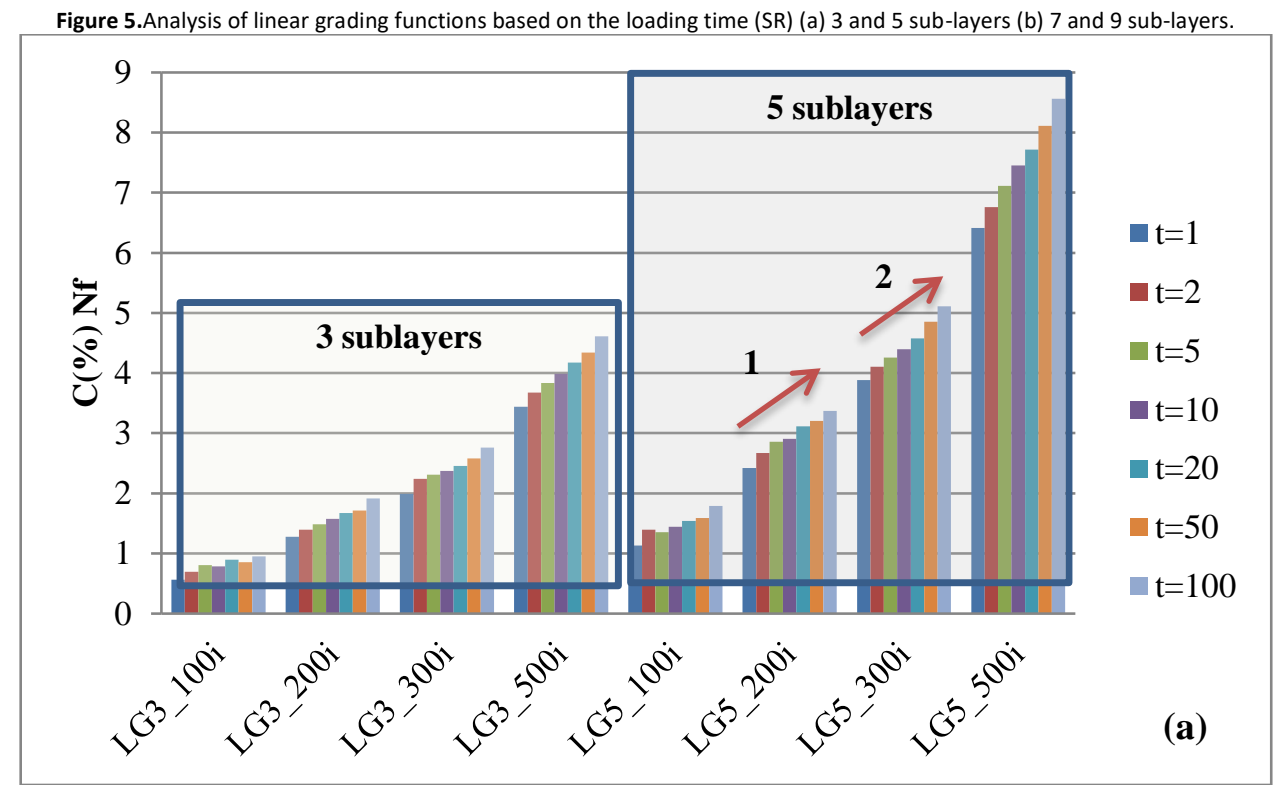



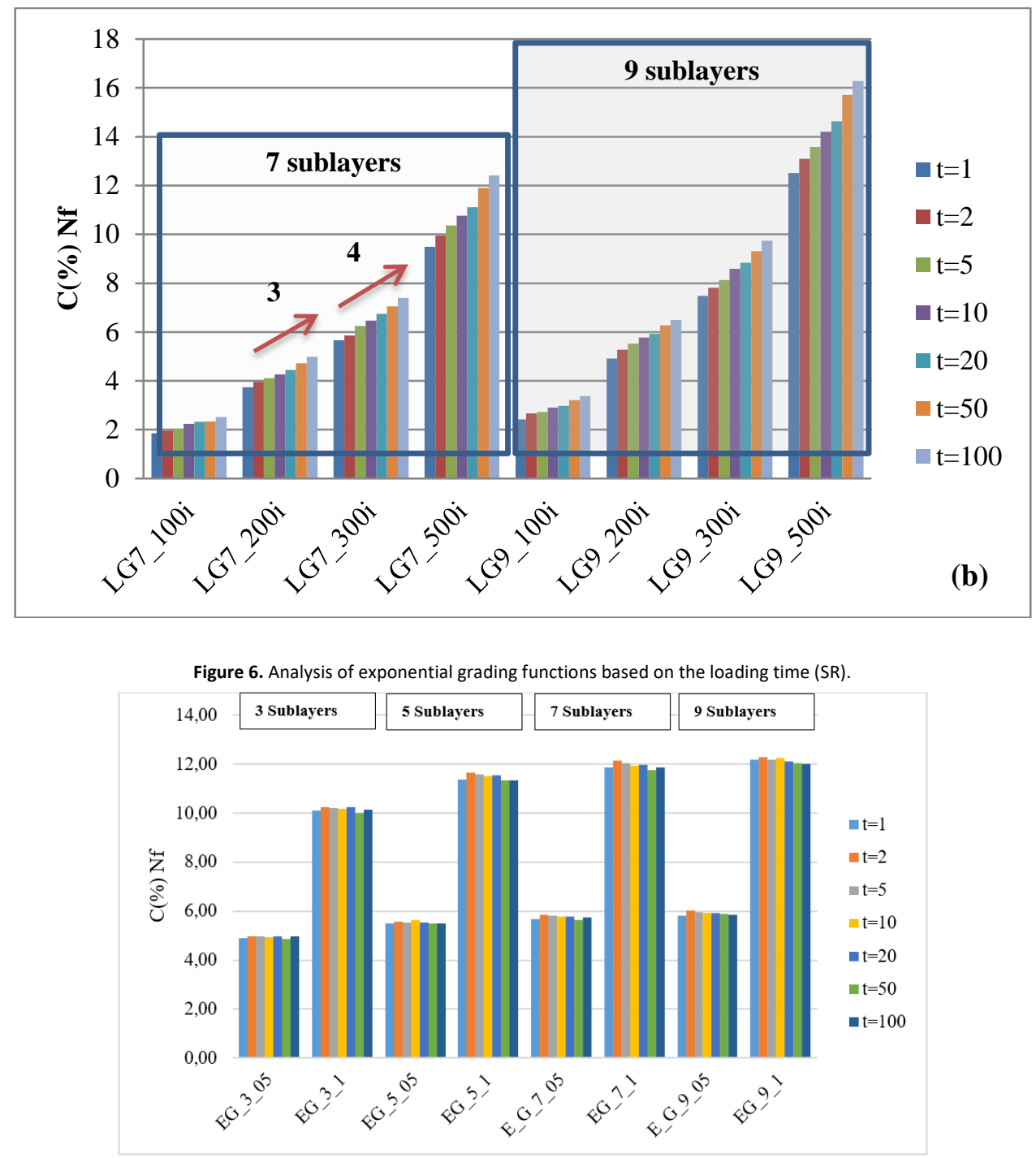

For $\mathrm{t}=1 \mathrm{sec}$, the comparison of linear and exponential grading functions based on the number of sub-layer is given in Figure 7.

When Figure 7 is examined, it is seen that the exponential grading provides higher $\mathrm{C}(\%)$ values with fewer sub-layer numbers. The number of sub-layers providing the $C(\%)$ value to be 10 (shown in dashed lines in Figure 9 ) is calculated as 7.37 for the linear grading and $\mathbf{2 . 7 8}$ for the exponential grading according to the graphic equations.According to these results, it can be said that exponential grading, which provides higher recovery with the less sub-layer number, is an effective method in increasing the fatigue strength and life of flexible pavements.

To determine the efficiency of functional grading under increasing load (loading radius) and loading time conditions, mechanical analyses were performed using different loading times and contact radii. In these analyses, the sections EG_3_1, EG_5_1, LG3_500i, and LG5_500i were used which are thought to be more feasible in field studies because of fewer sub-layers. $C(\%)$ values obtained are given in Figure 8-11.

When Figure 8 is examined, C(\%) values increased for all loading times due to CR increase for section EG_3_1. Accordingly, it can be said that the exponential grading performs well due to the increase in axle load and loading radius. When the effect of loading time on the EG_3_1 section is evaluated, no net increase or decrease was detected. In the graph, the points where $C(\%)$ is maximally determined are 10.56 for $t=5 \mathrm{sec}$ and $\mathrm{CR}=15.5 \mathrm{~cm}$ and 10.54 for $\mathrm{t}=2 \mathrm{sec}$ and $\mathrm{CR}=14.5 \mathrm{~cm}$. 
Figure 7. Comparison of linear and exponential graded sections depending on the number of sub-layers (for $t=1 \mathrm{sec}$ ) (SR).

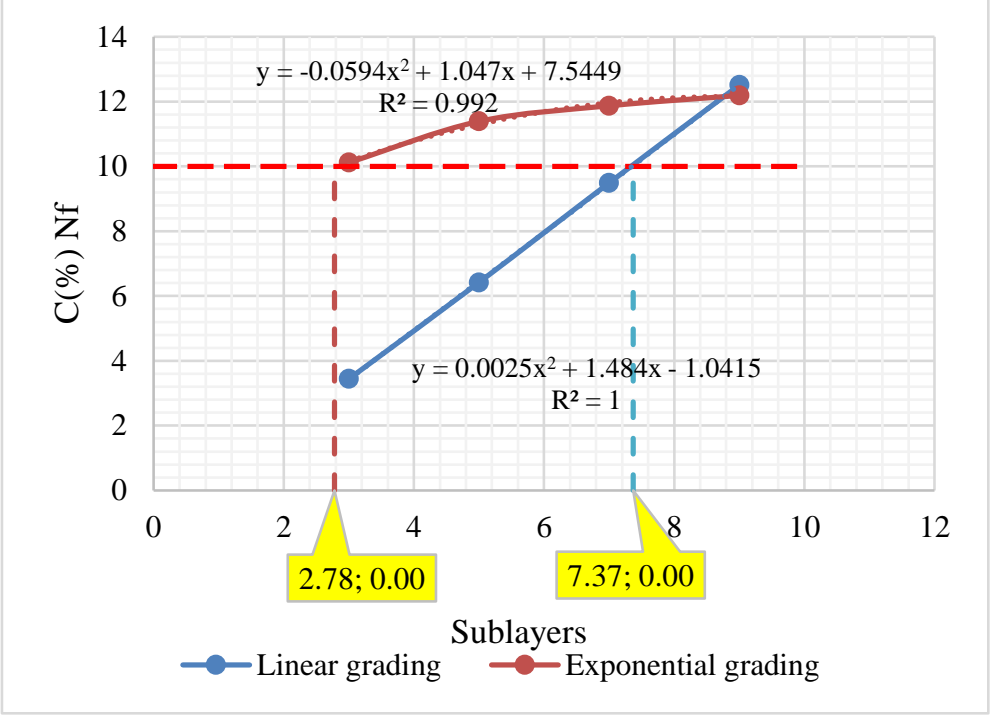

Figure 8. Contact radius and loading time analysis for section EG_3_1 (SR)

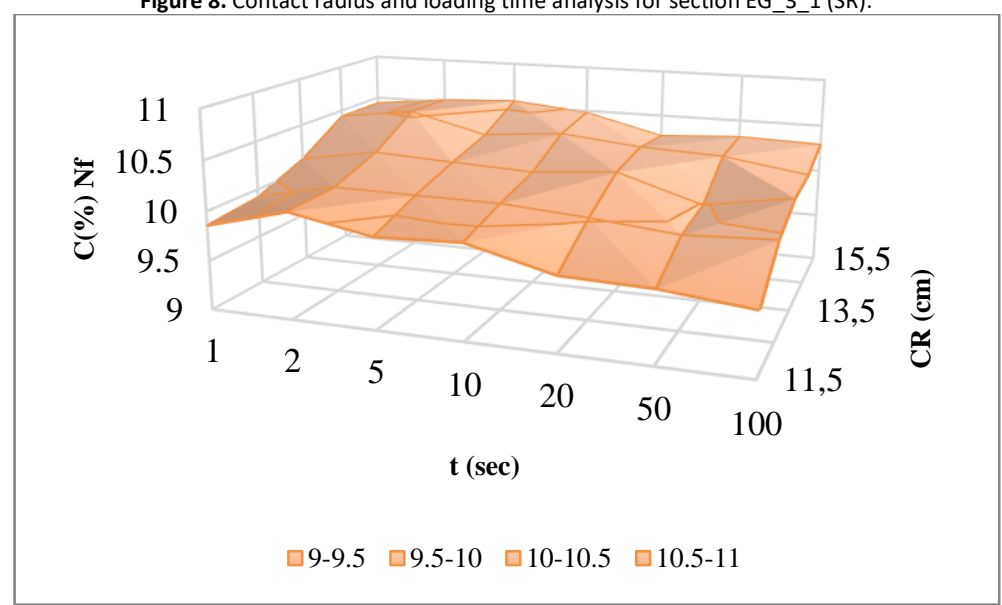

Figure 9. Contact radius and loading time analysis for section EG_5_1 (SR)

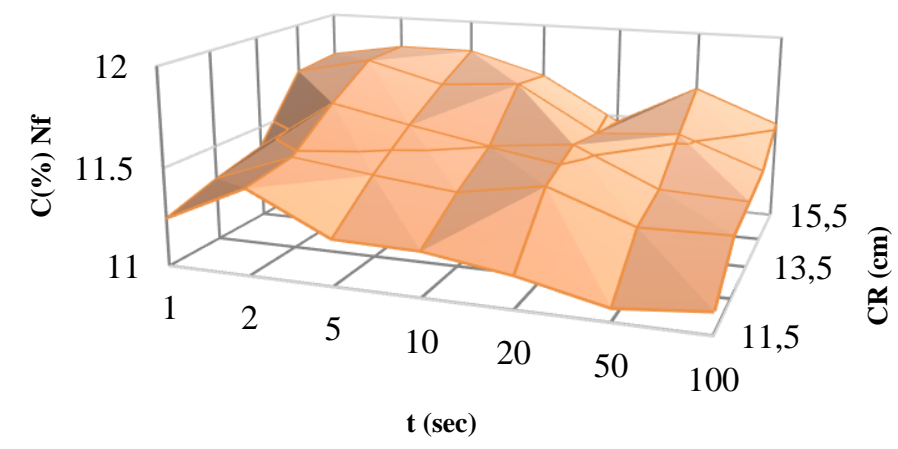

$\square 11-11.5 \quad \square 11.5-12$

When Figure 9 is analyzed, $\mathrm{C}(\%)$ values increased for all loading times due to the increase in loading radius in section EG_5_1. As in section EG_3_1, the highest C(\%) values were obtained for $t=2 \mathrm{sec}$ and $\mathrm{t}=5$ sec. The highest $\mathrm{C}(\%)$ values were determined as 11.83 for $t=2$ and $5 \mathrm{sec}$ and $C R=15.5 \mathrm{~cm}$. According to these values, the number of sub-layers increased from 3 to 5 , increasing the $C(\%)$ value from 10.56 to 11.83 . Depending on the load time change, no significant result was obtained as in section EG_3_1. 
Figure 10. Contact radius and loading time analysis for section LG3_500i (SR)

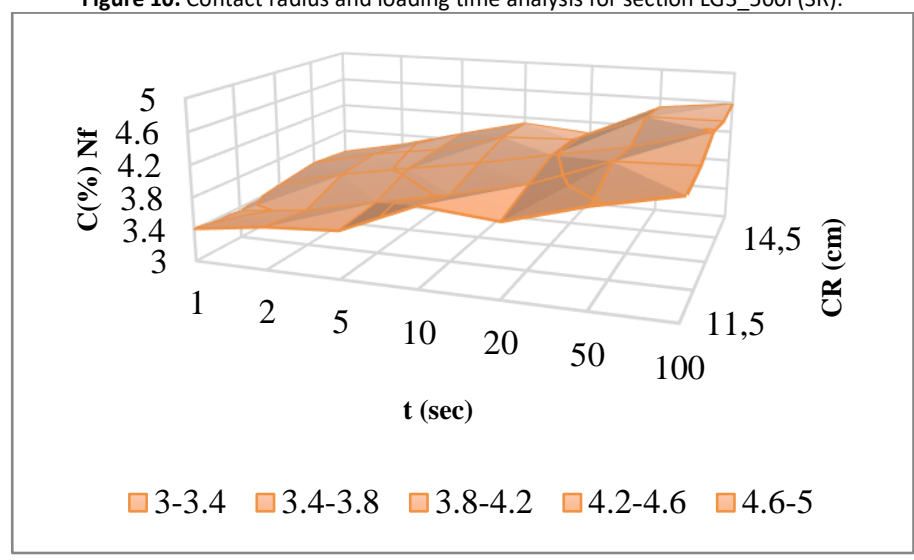

Figure 11. Contact radius and loading time analysis for section LG5_500i (SR).

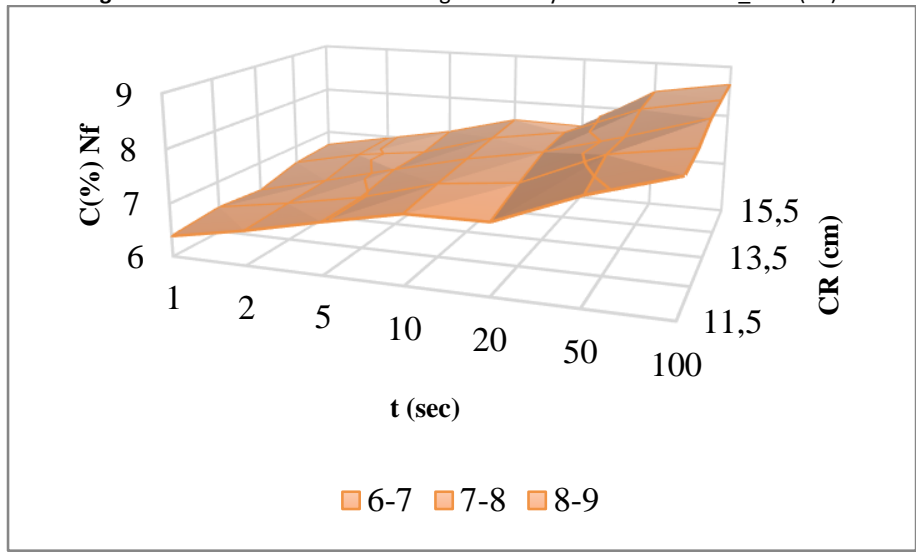

When figures 10 and 11 are evaluated together, it is seen for all loading radii that the $C(\%)$ values increase as loading time increases in linear graded sections. Depending on the loading radius, no significant change was detected in both sections.

Combinations with the highest $C(\%)$ values were determined as $t=100 \mathrm{sec}$ and $\mathrm{CR}=13.5 \mathrm{~cm}$ for the section LG_3_500i and $t=100 \mathrm{sec}$ and $C R=13.5 \mathrm{~cm}$ for the section LG_5_500i $(C \%=8.64)$. It is seen that these values obtained by linear grading are lower than those obtained in exponentially graded sections with the same sub-layer number.

Another method that can be used to express the axle load increase in the flexible pavements is to increase contact pressure in the same loading radius. Graphs showing the $\mathrm{C}(\%)$ change depending on the contact pressure change for the EG_3_1 and LG3_500i sections are given in Figures 12 and 13 . When the figures 12 and 13 are examined, a meaningful $\mathrm{C}(\%)$ change due to contact pressure change was not detected in the sections with exponential grading. In the section with linear grading, it can be said that $C(\%)$ values do not show excessive change and remain almost constant. Accordingly, it can be said that the functional grading process makes a contribution independent of the contact pressure.

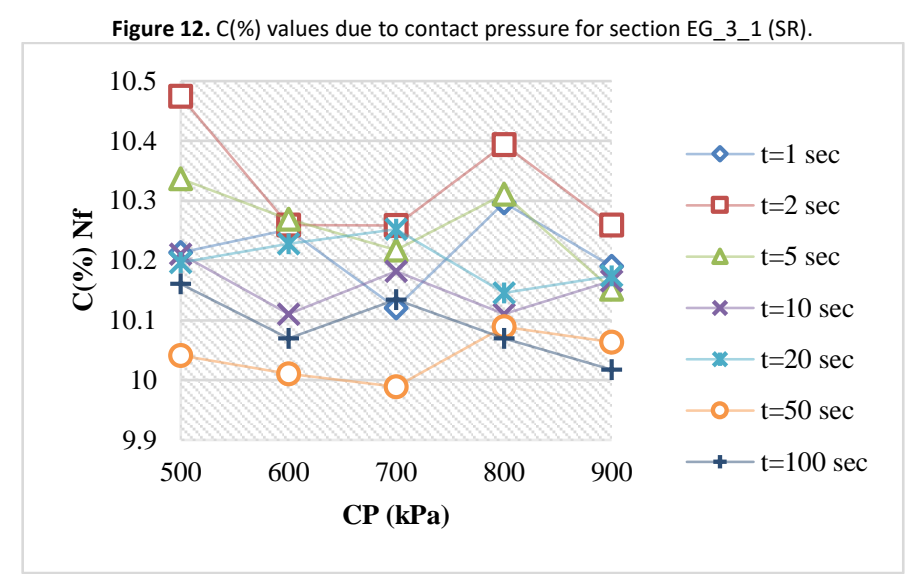




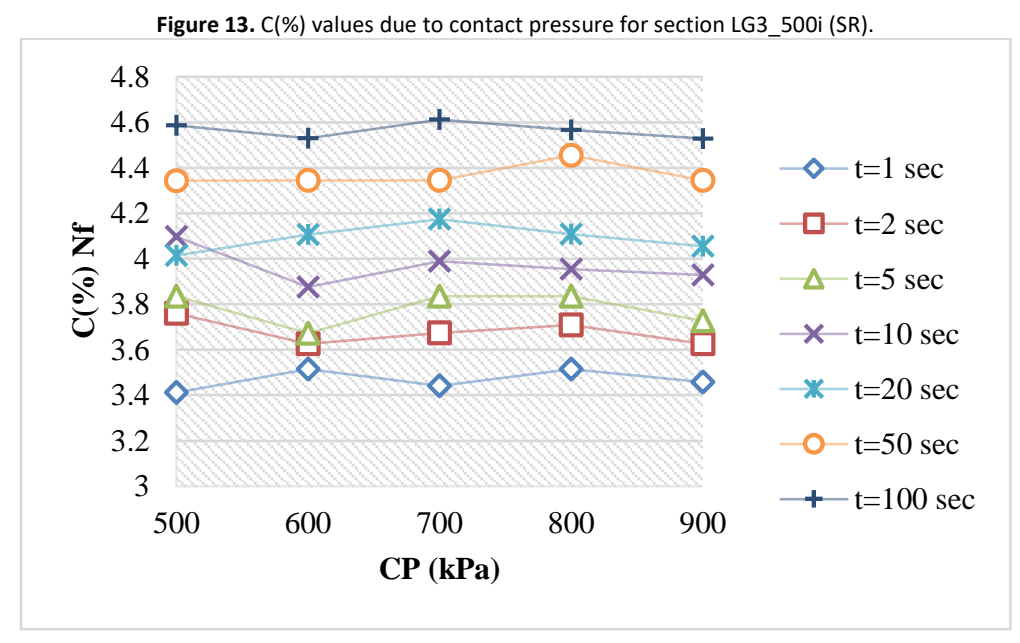

Conclusions

When the findings obtained from this study, where the viscoelastic defined HMA layer is graded with linear and exponential functions and analyzed mechanically, the following conclusions can be reached;

- Functional grading is a method that can be applied successfully to improve the mechanical properties of viscoelastic defined materials. Thanks to this method, the pavement life values can be significantly increased against deterioration, such as fatigue and rutting. In the functional grading system, there is no additional cost theoretically for the improvement achieved because of the average stiffness of the relevant layer does not change. Therefore, functional grading is a more advantageous method than methods in which the performance of flexible pavements is increased by additives.

- The main type of deterioration to which the pavement is subjected should be analyzed well when performing functional grading. The direction of stiffness increase or decrease of the sub-layers should be chosen according to this critical deterioration type. While fatigue strength improves in applications where stiffness is increased from top to bottom, rutting strength improves in applications where it decreases.

- The number of sub-layer is an important parameter affecting the result in the functional grading method. As the number of sub-layers increases, the deterioration resistance of the pavement increases. However, in real field applications, it is unrealistic to divide an HMA layer into multiple sub-layers ( 7 or 9 sub-layers). But, in the field applications of HMA, three sub-layers are already applied as surface, binder, and bituminous base. Accordingly, 3 or 5 sub-layers can be practiced easily in the field.

- To briefly summarize the results obtained from the study; As a result of the functional grading of the viscoelastic AC layer with increased rigidity in the z-direction, an increase in fatigue strength reaching $16.3 \%$ has been achieved. Increased number of sub-layers in both linear and exponential grading functions increased fatigue strength, but exponential grading function yielded more effective results even with fewer sub-layers. The increase in the $E(t)$ value in the linear grading process and the increase in the inhomogeneity coefficient in the exponential grading process increased the pavement life due to fatigue. In the analyzes based on loading time, the linear grading function gave better results as the loading time increased, while the exponential grading function was not significantly affected by the loading time. It can be said that the exponential grading function provides a higher pavement life value under increasing load and contact radius conditions.

- In the current study, creep compliance values were used for only one temperature value. The functional grading approach can be applied with creep compliance values at different temperatures and for increasing the rutting resistance. Also, more than one layer can be graded functionally rather than just grading the AC layer. Thus, the approach of strengthening more cross sections can be proposed for future studies in this area.

References

Abd Alla, E. M. (2006). The rational use of finite element method in the analysis of flexible pavements. Journal of Engineering Sciences, 34(4), 11851211.

Ahmed, A., \& Erlingsson, S. (2016). Viscoelastic response modelling of a pavement under moving load. Transportation Research Procedia, 14, 748757. Retrieved from http://dx.doi.org/10.1016/j.trpro.2016.05.343

Aktaş, B., Aytekin, Ş., \& Aslan, Ş. (2019). Evaluation of typical wma additives on design parameters of SMA mixtures. Revista de La Construccion, 18(3), 409-417. Retrieved from https://doi.org/10.7764/RDLC.18.3.409 
Ali, H. A. Tayabji, S. D. (1998). Mechanistic evaluation of test data from LTPP flexible pavement test sections.

Ambassa, Z., Allou, F., Petit, C., \& Eko, R. M. (2013). Fatigue life prediction of an asphalt pavement subjected to multiple axle loadings with viscoelastic FEM. Construction and Building Materials, 43, 443-452. Retrieved from https://doi.org/10.1016/j.conbuildmat.2013.02.017

Ashwinkumar A kokanee. (2017). Review on Functionally Graded Materials and various theories. International Research Journal of Engineering and Technology (IRJET), 890-893.

Behiry, A. E. A. E. M. (2012). Fatigue and rutting lives in flexible pavement. Ain Shams Engineering Journal, 3(4), 367-374. Retrieved from http://dx.doi.org/10.1016/j.asej.2012.04.008

Bostancioğlu, M. (2019). Effect of functional grading on the performance of flexible pavements. International Journal of Pavement Engineering, 1-10. Retrieved from https://doi.org/10.1080/10298436.2019.1623403

Chakraborty, A., Gopalakrishnan, S., \& Reddy, J. N. (2003). A new beam finite element for the analysis of functionally graded materials. International Journal of Mechanical Sciences, 45(3), 519-539. Retrieved from https://doi.org/10.1016/S0020-7403(03)00058-4

Chegenizadeh, A., Keramatikerman, M., \& Nikraz, H. (2016). Flexible pavement modelling using Kenlayer. Electronic Journal of Geotechnical Engineering, 21(7), 2467-2479.

Chen, E. Y. G., Pan, E., \& Green, R. (2009). Surface loading of a multilayered viscoelastic pavement: Semianalytical solution. Journal of Engineering Mechanics, 135(6), 517-528. Retrieved from https://doi.org/10.1061/(ASCE)0733-9399(2009)135:6(517)

Christensen, D. W., \& Bonaquist, R. F. (2004). Evaluation of Indirect Tensile Test (IDT) Procedures for Low-Temperature Performance of Hot Mix Asphalt. Evaluation of Indirect Tensile Test (IDT) Procedures for Low-Temperature Performance of Hot Mix Asphalt. Retrieved from 10.17226/13775

Çömez, I. (2015). Contact problem for a functionally graded layer indented by a moving punch. International Journal of Mechanical Sciences, 100, 339-344. Retrieved from https://doi.org/10.1016/j.ijmecsci.2015.07.006

Dave, E. V., Paulino, G. H., \& Buttlar, W. G. (2011). Viscoelastic Functionally Graded Finite-Element Method Using Correspondence Principle. Journal of Materials in Civil Engineering, 23(1), 39-48. Retrieved from https://doi.org/10.1061/(ASCE)MT.1943-5533.0000006

Demirbas, M. D. (2017). Thermal stress analysis of functionally graded plates with temperature-dependent material properties using theory of elasticity. Composites Part B: Engineering, 131, 100-124. Retrieved from https://doi.org/10.1016/j.compositesb.2017.08.005

Gedafa, D. S. (2006). Comparison of flexible pavement performance using KENLAYER and HDM-4. In Fall Student Conference (pp. 1-14). Ames, lowa: Midwest Transportation Consortium.

Ghadimi, B., \& Nikraz, H. (2017). A comparison of implementation of linear and nonlinear constitutive models in numerical analysis of layered flexible pavement. Road Materials and Pavement Design, 18(3), 550-572. Retrieved from https://doi.org/10.1080/14680629.2016.1182055

Ghayesh, M. H. (2018). Dynamics of functionally graded viscoelastic microbeams. International Journal of Engineering Science, $124,115-131$.

Giannakopoulos, A. E., \& Pallot, P. (2000). Two-dimensional contact analysis of elastic graded materials. Journal of the Mechanics and Physics of Solids, 48(8), 1597-1631. Retrieved from https://doi.org/10.1016/S0022-5096(99)00068-X

Guler, M. A., \& Erdogan, F. (2004). Contact mechanics of graded coatings. International Journal of Solids and Structures, 41(14), 3865-3889. Retrieved from https://doi.org/10.1016/j.ijsolstr.2004.02.025

Hadi, M. N. S., \& Bodhinayake, B. C. (2003). Non-linear finite element analysis of flexible pavements. Advances in Engineering Software, 34(11-12), $657-662$.

Hilton, H. H., \& Lee, D. H. (2012). Designer Functionally Graded Viscoelastic Materials Performance Tailored To Minimize Probabilistic Failures in Panels Subjected To Aerodynamic Noise. Journal of Aeroelasticity and Structural Dynamics, 2(3), 1-31. Retrieved from https://doi.org/10.3293/asdj.v2i3.9

Huang, Y. H. (2004). Pavement Analysis and Design (2nd ed.). Upper Saddle River, NJ: Pearson Prentice Hall.

Jeong, M. (2005). Comparison of Creep Compliance Master Curve Models for Hot Mix Asphalt. Virginia Tech. Retrieved from https://pdfs.semanticscholar.org/c2dc/0caecf7cf4145dbfae198d138b98b177c360.pdf

Jin, Z. H., \& Paulino, G. H. (2002). A viscoelastic functionally graded strip containing a crack subjected to in-plane loading. Engineering Fracture Mechanics, 69(14-16), 1769-1790.

Kahya, V., \& Turan, M. (2017). Finite element model for vibration and buckling of functionally graded beams based on the first-order shear deformation theory. Composites Part B: Engineering, 109, 108-115. Retrieved from https://doi.org/10.1016/j.compositesb.2016.10.039

Koohmishi, M. (2013). Comparison of Pavement Layers Responses with Considering Different Models for Asphalt Concrete Viscoelastic Properties. Slovak Journal of Civil Engineering, 21(2), 15-20. Retrieved from https://doi.org/10.2478/sjce-2013-0008

Liu, T. J., \& Wang, Y. S. (2008). Axisymmetric frictionless contact problem of a functionally graded coating with exponentially varying modulus. Acta Mechanica, 199, 151-165.

Liu, T. J., Wang, Y. S., \& Zhang, C. (2008). Axisymmetric frictionless contact of functionally graded materilas. Archive of Applied Mechanics, 78, 267282.

Mahamood, R. M., Akinlabi, E. T., Shukla, M., \& Pityana, S. (2012). Functionally graded material: An overview. Lecture Notes in Engineering and Computer Science, 3, 1593-1597.

Marasteanu, M., Zofka, A., Turos, M., Li, X., Raul, Velasquez, ... McGraw, J. (2012). Investigation of Low Temperature Cracking in Asphalt Pavements. Retrieved from Minnesota: 
Mejłun, Ł., Judycki, J., \& Dołzycki, B. (2017). Comparison of Elastic and Viscoelastic Analysis of Asphalt Pavement at High Temperature. Procedia Engineering, 172, 746-753. Retrieved from https://doi.org/10.1016/j.proeng.2017.02.095

Mistry, R., \& Roy, T. K. (2020). Predicting Marshall stability and flow of bituminous mix containing waste fillers by the adaptive neuro-fuzzy inference system. Revista de La Construccion, 19(2), 209-219. Retrieved from https://doi.org/10.7764/RDLC.19.2.209

Miteva, A. M. (2014). An overview of the functionally graded materials. Machines. Technologies. Materials, 8(3), 13-16.

Moreno, M. A. R., Navarro, T. E., \& Zeballos, G. T. (2017). Including reliability in the AASHTO-93 flexible pavement design method integrating pavement deterioration models. Revista de La Construccion, 16(2), 284-294. Retrieved from https://doi.org/10.7764/RDLC.16.2.284

Mousa, M. R., Abo-Hashema, M. A., Gadallah, A. A., \& Mousa, R. M. (2015). Evaluation of pavement performance prediction models under different traffic and climatic conditions. In 14th International Conference on Asphalt, Pavement Engineering, and Infrastructure. (pp. 1-19).

Muniandy, R., Aburkaba, E., \& Thamer, N. (2013). Comparison of flexible pavement performance using Kenlayer and Chev PC software program. Australian Journal of Basic and Applied Sciences, 7(9), 112-119.

Ng, K., Henrichs, Z. R., Ksaibati, K., \& Wulff, S. S. (2018). Resilient modulus of subgrade materials for mechanistic-empirical pavement design guide. Road Materials and Pavement Design, 19(7), 1523-1545. Retrieved from https://doi.org/10.1080/14680629.2017.1323662

Ramirez, F., Heyliger, P. R., \& Pan, E. (2006). Static analysis of functionally graded elastic anisotropic plates using a discrete layer approach. Composites Part B: Engineering, 37(1), 10-20. Retrieved from https://doi.org/10.1016/j.compositesb.2005.05.009

Richardson, D. N., \& Lusher, S. M. (2008). Determination of Creep Compliance and Tensile Strength of Hot-Mix Asphalt for Wearing Courses in Missouri. Missouri Department of Transportation, (July)

Safi, F. R., Hossain, K., Wu, S., Al-Qadi, I. L., \& Ozer, H. (2018). A model to predict creep compliance of asphalt mixtures containing recycled materials. Construction and Building Materials, 184, 374-381. Retrieved from https://doi.org/10.1016/j.conbuildmat.2018.06.232

Singh, A. K., \& Sahoo, J. P. (2020). Analysis and design of two layered flexible pavement systems: A new mechanistic approach. Computers and Geotechnics, 117(September 2019), 103238. Retrieved from https://doi.org/10.1016/j.compgeo.2019.103238

Titi, H. H., \& Matar, M. G. (2018). Estimating resilient modulus of base aggregates for mechanistic-empirical pavement design and performance evaluation. Transportation Geotechnics, 17(August), 141-153. Retrieved from https://doi.org/10.1016/j.trgeo.2018.09.014

Xu, X. J., \& Meng, J. M. (2018). A model for functionally graded materials. Composites Part B: Engineering, 145(November 2017), 70-80. Retrieved from https://doi.org/10.1016/j.compositesb.2018.03.014

Zhang, L., \& Yang, H. (2020). A 2-D numerical analysis for the structure composed by viscoelastic functionally graded materials using a temporally piecewise adaptive algorithm. Applied Mathematical Modelling, 81, 441-456. Retrieved from https://doi.org/10.1016/j.apm.2020.01.015 